\title{
CREST-Snow Field Experiment: analysis of snowpack properties using multi-frequency microwave remote sensing data
}

\author{
T. Y. Lakhankar ${ }^{1}$, J. Muñoz ${ }^{1}$, P. Romanov ${ }^{1}$, A. M. Powell ${ }^{2}$, N. Y. Krakauer ${ }^{1}$, W. B. Rossow ${ }^{1}$, and R. M. Khanbilvardi ${ }^{1}$ \\ ${ }^{1}$ NOAA- Cooperative Remote Sensing Science and Technology Center (NOAA-CREST), The City College of New York, \\ 160 Convent Ave, New York, NY 10031, USA \\ ${ }^{2}$ NOAA/NESDIS/Center for Satellite Applications and Research (STAR), 5200 Auth Road, WWB, Camp Springs, \\ MD 20746, USA
}

Correspondence to: T. Y. Lakhankar (tlakhankar@ccny.cuny.edu)

Received: 30 May 2012 - Published in Hydrol. Earth Syst. Sci. Discuss.: 4 July 2012

Revised: 26 December 2012 - Accepted: 29 January 2013 - Published: 22 February 2013

\begin{abstract}
The CREST-Snow Analysis and Field Experiment (CREST-SAFE) was carried out during January-March 2011 at the research site of the National Weather Service office, Caribou, ME, USA. In this experiment dual-polarized microwave ( 37 and $89 \mathrm{GHz}$ ) observations were accompanied by detailed synchronous observations of meteorology and snowpack physical properties. The objective of this long-term field experiment was to improve understanding of the effect of changing snow characteristics (grain size, density, temperature) under various meteorological conditions on the microwave emission of snow and hence to improve retrievals of snow cover properties from satellite observations. In this paper we present an overview of the field experiment and comparative preliminary analysis of the continuous microwave and snowpack observations and simulations. The observations revealed a large difference between the brightness temperature of fresh and aged snowpack even when the snow depth was the same. This is indicative of a substantial impact of evolution of snowpack properties such as snow grain size, density and wetness on microwave observations. In the early spring we frequently observed a large diurnal variation in the 37 and $89 \mathrm{GHz}$ brightness temperature with small depolarization corresponding to daytime snowmelt and nighttime refreeze events. SNTHERM (SNow THERmal Model) and the HUT (Helsinki University of Technology) snow emission model were used to simulate snowpack properties and microwave brightness temperatures, respectively. Simulated snow depth and snowpack temperature using SNTHERM were compared to in situ observations. Similarly, simulated microwave brightness temperatures using the HUT model
\end{abstract}

were compared with the observed brightness temperatures under different snow conditions to identify different states of the snowpack that developed during the winter season.

\section{Introduction}

The storage of water in snowpack affects runoff and soil moisture, and is therefore important at the regional scale for various hydrologic applications as flood prediction and water resource management. Rain on snow combined with warm air temperatures can lead to fast snowmelt. These conditions are responsible for the majority of spring floods in mid- and high-latitude areas (Erman et al., 1988; McCabe et al., 2007; Papa et al., 2007; Singh et al., 1997). Snowpack is a complex medium with large spatial and temporal variability. It can consist of several layers with different densities and snow grain size distributions. An adequate knowledge of the snow depth and the snow water equivalent (SWE) is necessary to model hydrology, meteorology, and climate (McCabe et al., 2007).

Satellite observations in the microwave spectral range have been used for the global monitoring of snow cover properties for more than three decades. Microwave emission from snowpack depends on the snow grain size, density, depth, snowpack and soil temperature, along with snow and soil wetness (Grody, 2008). Deeper snow increases the scatter of the microwave signal and hence causes lower scene microwave brightness temperature (Ulaby and Stiles, 1980). Larger snow grain sizes corresponding to aged or melted and 
refrozen snowpack also increase scattering and reduce the brightness temperature (Grody, 2008). In addition, the evolution of snowpack temperature and soil temperature throughout the winter season as they affect microwave emission (Brucker et al., 2011) are not well studied. As well, microwave emission of wet snow depends on the liquid water content in the snowpack. Therefore, the snow profile physical temperature can be critical to interpreting microwave signals during the spring melting and refreezing period (Chang et al., 2003).

In a large number of studies, brightness temperature in 19 , 37 and $85 / 89 \mathrm{GHz}$ frequency bands from the Special Microwave Imager (SSM/I) and Advanced Microwave Scanning Radiometer (AMSR-E) have been used to estimate the snow depth or the snow water equivalent (Durand et al., 2008; Grody and Basist, 1996; Kelly et al., 2003; Romanov et al., 2000; Simic et al., 2004). Earlier snow depth retrieval algorithms (Chang et al., 2003; Foster et al., 1997) provided an "instantaneous" snow depth estimate using the gradient in microwave brightness temperature values between $19 \mathrm{GHz}$ and $37 \mathrm{GHz}$ bands. Several models have been proposed to more fully describe the relationships between microwave emission and snow parameters such as mean snow grain size, density, and depth (Grody, 2008; Kelly et al., 2003; Pulliainen et al., 1999; Wiesmann and Mätzler, 1999).

Accurate estimation of the snow grain size and density (Kelly et al., 2003), soil temperature, (Brucker et al., 2011) and other parameters is needed to improve the performance of a snow emission model (Langlois et al., 2009). In situ observations of the microwave emission of snow, coupled with other meteorological and snowpack measurements, are critical in the development and validation of algorithms to retrieve snow depth or SWE from remote sensing measurements in the microwave. Earlier snow field experiments (Chang et al., 1981; Elder et al., 2009; Hewison and English, 1999; Langlois et al., 2007; Macelloni et al., 2005) have used microwave radiometers to study snowpack microwave emission properties. Conducting such experiments is important to improve understanding of the complex influence of different snow characteristics (grain size, density, snow temperature) on the microwave emission and on snow retrievals from microwave measurements.

This paper presents an overview of the CREST-Snow Analysis and Field Experiment (CREST-SAFE) and comparative preliminary analysis of snowpack observations during the 2011 winter season. The current experiment builds on earlier studies by extending over the full winter season instead of only one or a few days, thus allowing processes of snowpack accumulation, metamorphism, and melting - and their impacts on microwave emissivity - to be observed sequentially at the same site. The objective of this long-term field experiment was to characterize the behavior of snow-emitted microwave radiation throughout the winter season. In this experiment, ground microwave observations are collocated and synchronous with detailed observations of snowpack temperature. The effect of snowpack temperature (related to dry and wet snow conditions) on the microwave brightness temperature has been examined and interpreted.

\section{Description of field experiment and datasets}

The measurement site (Fig. 1) is located next to the Regional National Weather Service office on the premises of the Caribou Municipal Airport at Caribou, Maine, USA $\left(46^{\circ} 52^{\prime} 59^{\prime \prime} \mathrm{N}, 68^{\circ} 01^{\prime} 07^{\prime \prime} \mathrm{W}, 190\right.$ m elevation). Caribou, with a cool, humid continental climate, offers ideal conditions for snow studies. Historically, the cold season with an average daily high temperature below $0{ }^{\circ} \mathrm{C}$ lasts in the region from mid-December to early March. Snow cover is likely from mid-November to early April. The mean annual snowfall in Caribou is approximately $2.9 \mathrm{~m}$. The record seasonal snowfall in Caribou was $5.02 \mathrm{~m}$, set during the 2007-2008 winter season.

The set of instrumentation installed at the measurement site includes two dual-polarization microwave radiometers manufactured by Radiometrics Corporation (Boulder, CO, USA). The radiometers operating at 37 and $89 \mathrm{GHz}$ are mounted on top of a trailer at about $4 \mathrm{~m}$ height (Fig. 2a) and are pointed at the surface at an incidence angle of 55 degrees. The observation incidence angle was selected to match the observation geometry of Special Sensor Microwave Imager (SSMI) onboard DMSP satellites and Advanced Microwave Scanning Radiometer (AMSR-E) onboard Aqua satellite. The radiometer footprint is an elliptical shape with $2.6 \mathrm{~m}$ major axis and $1.2 \mathrm{~m}$ minor axis. The half antenna beam width of antenna is $3 \mathrm{~dB}$ and the radiometer stability is better than $2 \mathrm{~K}$. Both radiometers were calibrated using ambient temperature microwave absorber "warm reference" and liquid nitrogen as "cold reference" targets of known temperatures before and after the winter season to check for calibration drift. The error in the measurement of calibration target is less than $1 \mathrm{~K}$.

Measurements of the microwave brightness temperature at the two frequencies were taken routinely at one minute intervals. Observations of the temperature vertical distribution in the snowpack were measured with a specially developed temperature profiler. This instrument (Fig. 2b) was built with 16 Watlow Rigid Sheath Thermocouples placed at 5 to $10 \mathrm{~cm}$ intervals.

A number of additional datasets in support of the measurements at the CREST-SAFE were collected. Reference data for the snow depth consisted of daily in situ snow depth observations performed at the NWS weather station in Caribou. A snow grain size and snow density vertical profile at $15 \mathrm{~cm}$ intervals was measured on 10 March 2011. Estimated sensible and latent heat fluxes were used in this study to understand the heat transfer and temperature gradients across the snowpack and their impact on the microwave emission. Latent heat flux associated with energy transfer across the snow-air interface is a function of specific humidity. 


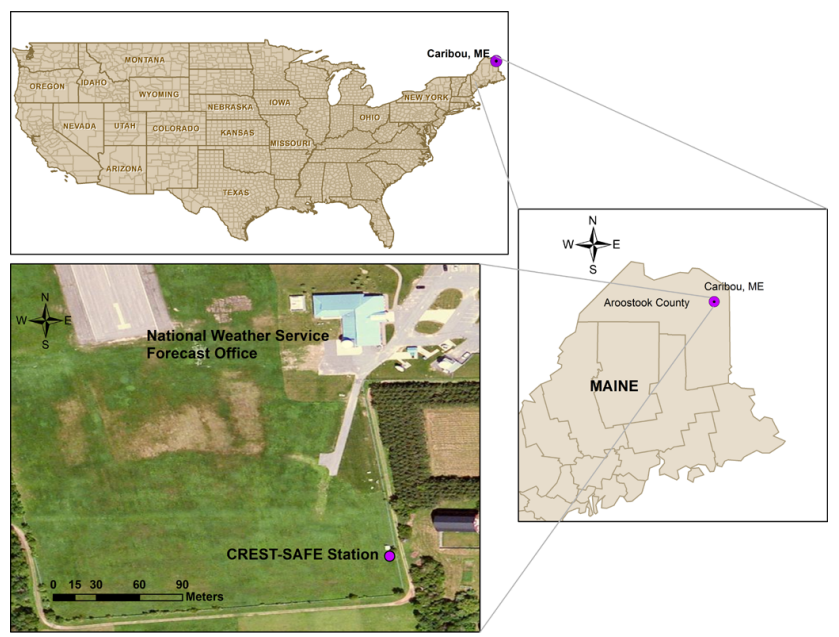

Fig. 1. CREST-SAFE location, near National Weather Service and Caribou Municipal Airport in Caribou, Maine.

Similarly, sensible heat flux is related to the magnitude of temperature differences between the atmosphere and the snow surface. Sensible and latent heat fluxes for the site location were obtained from National Operational Hydrologic Remote Sensing Center's snow model (NSM) (http://www. nohrsc.noaa.gov/interactive). NSM is an energy-and-massbalance, spatially-uncoupled, vertically-distributed, multilayer snow model, which ingests ground-based, airborne, satellite, numerical weather prediction (NWP) model, and radar data to produce hourly gridded snowpack state variables.

\section{Radiometric observations and interpretations}

\subsection{Analysis of snowpack microwave response}

Microwave brightness temperature, snowpack physical temperature, radiation flux and snow depth data acquired from the beginning of January to the end of March 2011 were analyzed. During this period, four major (snowfall greater than $10 \mathrm{~cm}$ ) and seven minor (snowfall less than $10 \mathrm{~cm}$ ) snowfall events were observed at the site. Cumulative snowfall over January-March 2011 was $85 \mathrm{~cm}$, while the maximum snow depth reached $50 \mathrm{~cm}$.

The observation time series were examined to quantitatively evaluate changes in the physical and microwave emission properties of the snowpack and to establish the relationship of the meteorological and snow physical parameters with recorded microwave brightness temperature. In order to better interpret, the time series of observation was split into three phases: initial accumulation (DOY 8-34), subfreezing and melting (DOY 35-56) and melting and refreezing phase (DOY 57-87) based on characteristics of the observed microwave response and snowpack temperature during the study period.

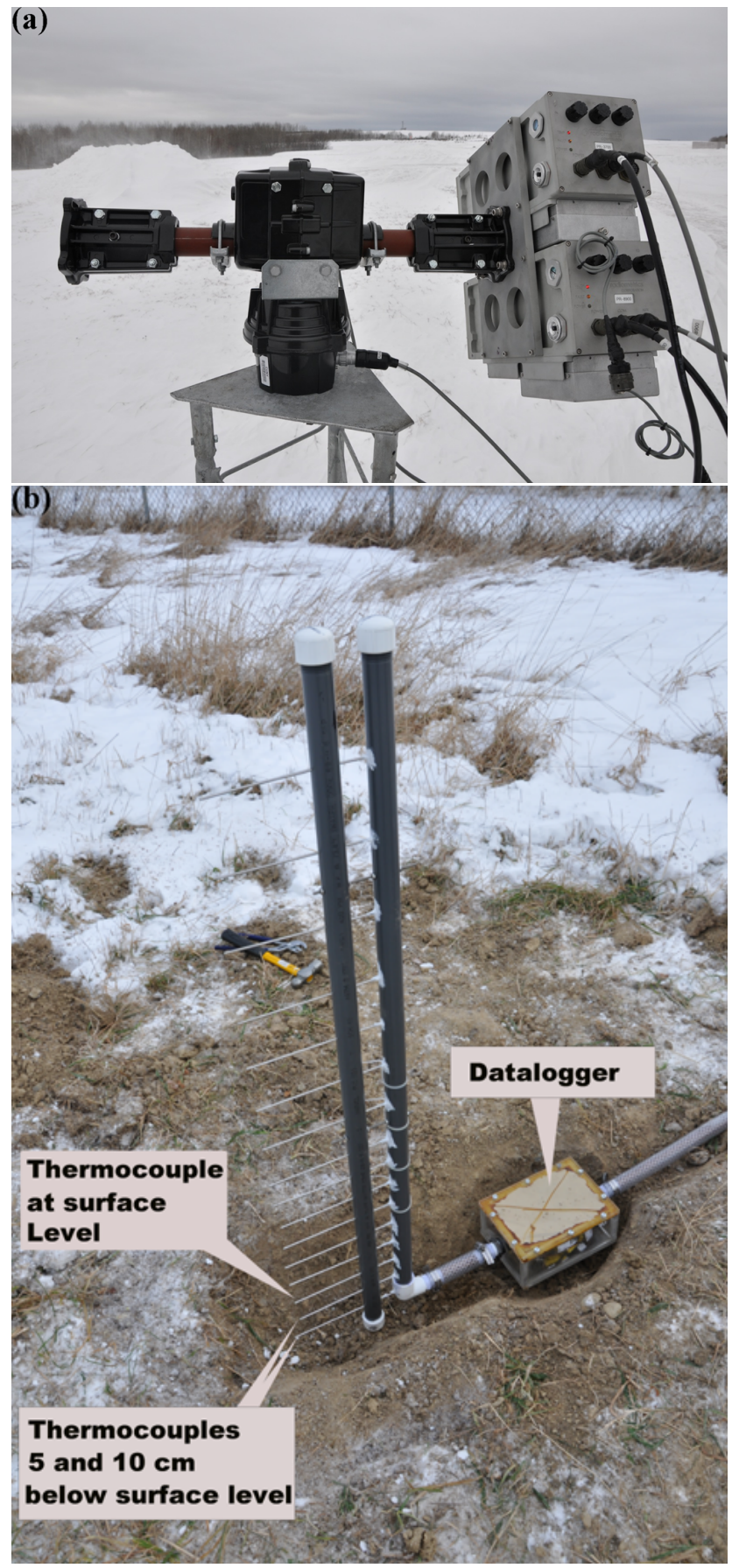

Fig. 2. (a) Microwave Radiometer ( 37 and $89 \mathrm{GHz}$ ) attached to automatic azimuth positioner. (b) Temperature profiler with 16 Watlow Rigid Sheath Thermocouples to measure air/snow temperature at defined depths.

These phases are plotted (Figs. 3-5) as a time series of (a) radiometric observations using the 37 and $89 \mathrm{GHz}$ radiometer in horizontal and vertical polarization (referred hereafter as $37 \mathrm{H}, 37 \mathrm{~V}, 89 \mathrm{H}$ and $89 \mathrm{~V}$ ), (b) sensible and latent heat flux, (c) integrated average snowpack temperature from 
temperature profiler, air temperature at $2 \mathrm{~m}$ from soil surface, and the difference between the soil temperature (at $10 \mathrm{~cm}$ depth) and the snowpack temperature, and (d) snowpack temperature gradient with respect to snow depth.

\subsubsection{Initial accumulation phase}

The initial accumulation phase ranged from DOY 8-34 and included 3 minor and 1 major snowfall events, leading to snow accumulation without snowmelt under mostly below freezing temperature conditions. The observed average, minimum and maximum snowpack temperature was 267.8 , 260.6 and $272.3 \mathrm{~K}$, respectively, indicating that melting did not take place. During this phase, a temperature gradient in the snowpack developed due to much lower air temperature as compared to the soil temperature below the snowpack, measured using temperature probe at soil surface level, which fluctuated between 268 and $272.9 \mathrm{~K}$. The average soil temperature during this period was $268.9 \mathrm{~K}$. Diurnal variations in brightness temperature corresponding to air temperature and snowpack temperature change were observed but were smaller compared to the late winter period.

The analysis of the time series of microwave observations during the accumulation period shows that the brightness temperature at $89 \mathrm{GHz}$ is more responsive to the snowpack temperature than the one at $37 \mathrm{GHz}$. Figure 3 illustrates changes in the snowpack temperature and corresponding changes in the microwave emission during the snow accumulation phase. The $89 \mathrm{GHz}$ brightness temperatures in both polarizations show higher sensitivity to snowpack changes associated with changes in the surface temperature and in grain size during the time period from DOY 15 to 19 (Event E1 in Fig. 3), when the snowpack was thin $(5 \mathrm{~cm})$. The reduction of TB in $89 \mathrm{GHz}$ band at both vertical and horizontal polarization during Event E1 was primarily associated with the change in the surface temperature accompanied with the change in snow grain size. During the period from DOY 7 to DOY 18 better correlation $(R=0.86)$ was observed between soil temperature versus brightness temperature $(37 \mathrm{~V}$ and $89 \mathrm{~V}$ ) in vertical polarization as compared to the horizontal polarization $(R=0.79)$. The observed brightness temperature at $37 \mathrm{H}$ shows some sensitivity to changes in the soil temperature (top $10 \mathrm{~cm}$ of soil below snow layer), whereas $\mathrm{TB}$ in the $37 \mathrm{~V}$ band remains insensitive to soil temperature.

The first major snow storm on DOY 19-20 added $12.5 \mathrm{~cm}$ of snow on site, which increased the snowpack depth to $17.5 \mathrm{~cm}$ (Event E2 in Fig. 3). The snowfall caused noticeable fluctuations and a general increase in the brightness temperature at $89 \mathrm{GHz}$. We believe that BT fluctuations at $89 \mathrm{GHz}$ are caused by falling snow particles and by the quick change of the snowflake shapes as they hit the ground or the top snow layer. The fact that BT fluctuations at $89 \mathrm{GHz}$ correspond to snowfall events was confirmed through the analysis of hourly precipitation data records obtained from NCDC. It was interesting to observe the increase of the brightness temperature
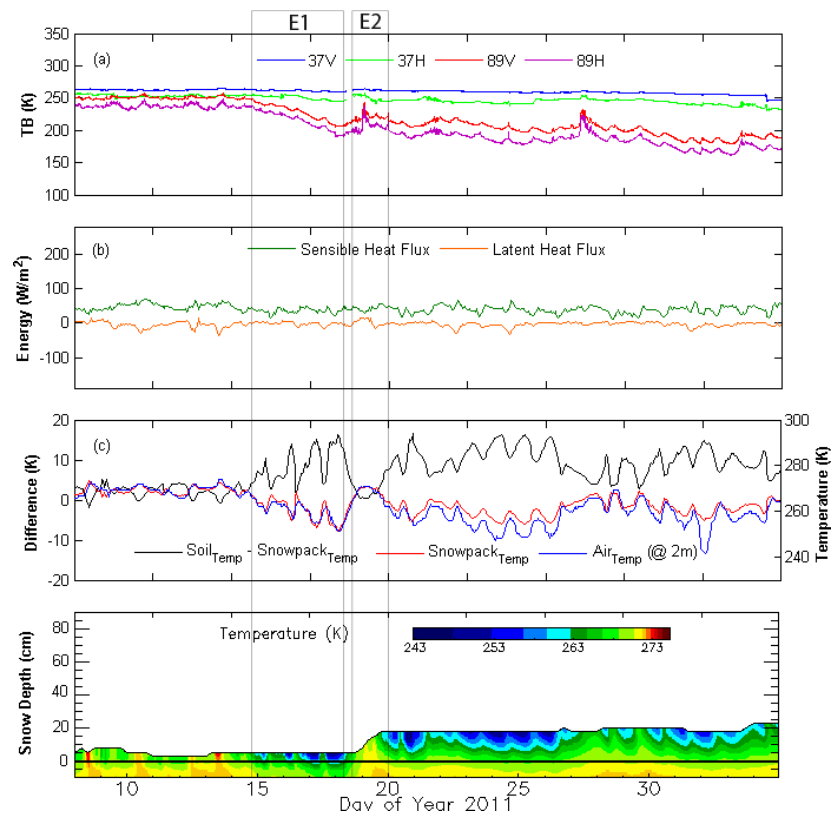

Fig. 3. Time series of observed radiometric and physical characteristics of snowpack snow accumulation phase in early winter period. (a) Microwave brightness temperature at 37 and $89 \mathrm{GHz}$ vertical and horizontal polarization, (b) modeled sensible heat flux and latent heat flux, (c) snow depth, air temperature at $2 \mathrm{~m}$ from surface, and integrated average snowpack temperature measured by temperature profiler, and (d) temperature measured at different depths below and above the ground surface.

at $89 \mathrm{GHz}$ immediately after the snowfall event, which will be investigated more fully in the next stage of the field experiment.

The snow depth remained at around $20 \mathrm{~cm}$ without snowmelt due to freezing temperature, with minor reduction in snow depth due to wind drift. Even though there was no significant change in the snow depth, the BT at $89 \mathrm{VH}$ gradually decreased over time. This reduction is apparently related to changes in the snowpack properties (Fig. 7) particularly to the increase of the grain size. The range of brightness temperatures measured in the $89 \mathrm{GHz}$ channels could help to distinguish between fresh and aged snow (Grody, 2008; Kongoli et al., 2004).

The increased polarization difference observed after DOY 20 at both 37 and $89 \mathrm{GHz}$ frequencies is the response to increased snow depth. This difference was mostly due to the increased horizontally polarized BT. Reflectivity in the vertical plane is smaller than in the horizontal plane due to the Brewster angle. The decreasing penetration depth and the increased scattering caused by the increasing grain size is the main cause of the higher variations in the $89 \mathrm{GHz}$ compared to $37 \mathrm{GHz}$ observations (Rosenfeld and Grody, 2000). Eleven days of below freezing temperatures on DOYs 2133 caused a slow snow metamorphic process resulting in a gradual increase of the grain size. The temperature gradient 

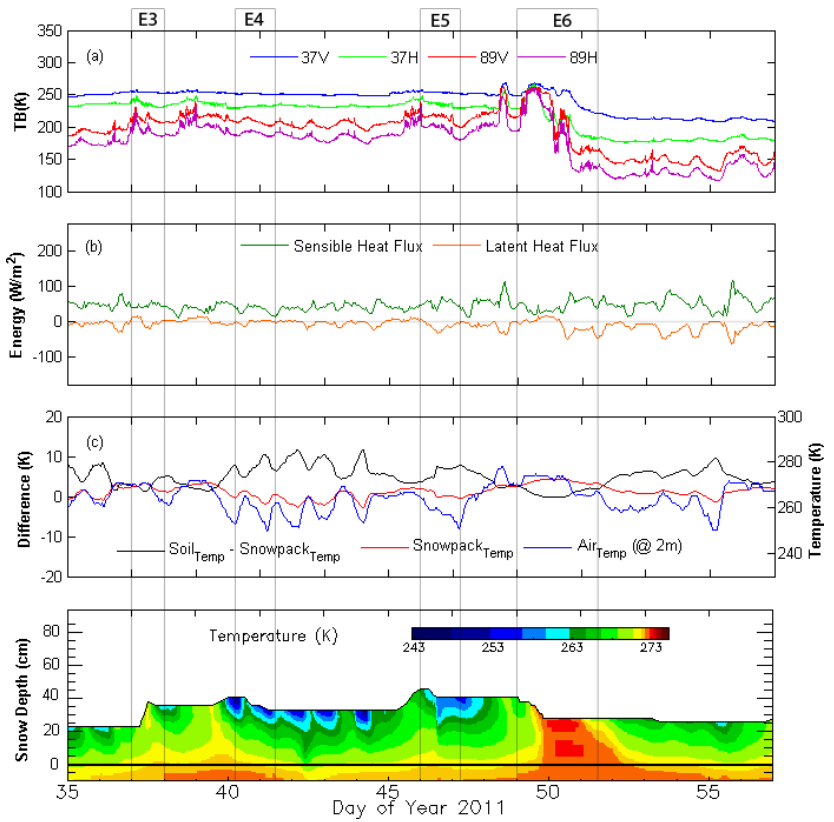

Fig. 4. Time series under accumulating and melting snow phases during mid-winter period. The quantities shown are the same as those described in Fig. 3.

in the snowpack was close to linear with temperatures changing from about $270 \mathrm{~K}$ at the bottom of snow (soil surface) to $\sim 250 \mathrm{~K}$ at the top of the snow surface. During this period, brightness temperatures gradually decreased by $10 \mathrm{~K}$ and $15 \mathrm{~K}$ for $37 \mathrm{GHz}$ at vertical and horizontal polarization, respectively. This fact shows that in thick snowpacks brightness temperature at horizontal polarization is more sensitive to the increase in the grain size than the brightness temperature at vertical polarization.

The latent and sensible heat flux data for the field location were plotted against observed snowpack data to understand if we can derive useful information related to major snowfall or snowmelt events. Through the snow accumulation phase average values of latent and sensible heat flux values were $38.0 \mathrm{~W} \mathrm{~m}^{-2}$ and $2.95 \mathrm{~W} \mathrm{~m}^{-2}$ (negative), respectively. This was associated with low air temperature that reduces near surface moisture gradients. The latent and sensible heat flux were very stable throughout this period. The lower value of latent heat flux is due to cooler air reducing the surface moisture gradient and preventing heat loss through sublimation.

\subsubsection{Subfreezing and melting phase}

The subfreezing and melting phase, from DOY 35-57, include 3 minor and 1 major snowfall events. During this phase reduction, in snow depth was due to major snowmelt on DOY $49(12.5 \mathrm{~cm}$ snow melted) and some minor reductions due to snow blowing by wind. The observed average, minimum and maximum snowpack temperature was 269.8, 266.1 and $272.6 \mathrm{~K}$, respectively. The average soil
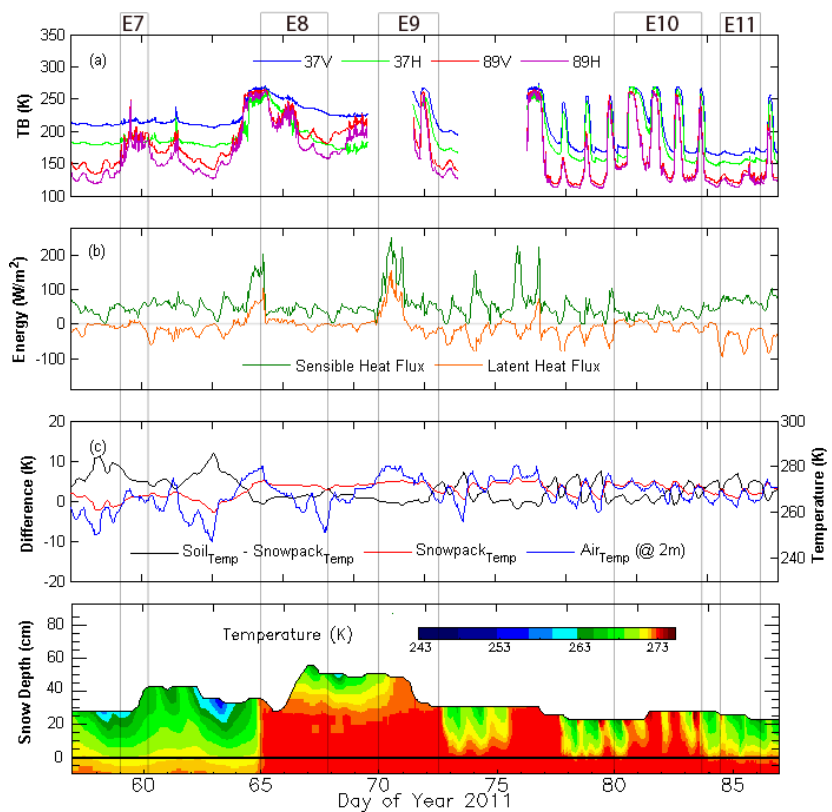

Fig. 5. Time series under melting and refreezing phase during late winter period of warm days (wet snow) and cold nights. The quantities shown are the same as those described in Fig. 3.

temperature during this period was $271.5 \mathrm{~K}$, measured using temperature probe at soil surface level, which is warmed up by $2.6 \mathrm{~K}$ compared to the snow accumulation phase. This increase in the temperature would have stimulated metamorphic processes that cause the formation of larger snow grains and eventually lead to the wet snow conditions at the bottom of the snowpack.

The time series of the brightness temperature (Figs. 3 and 4) at both frequencies demonstrate that the main contribution to variations in the recorded microwave brightness temperature for both dry and wet snow results from the variation of snowpack properties. Snow metamorphism, which transforms smaller grains into larger grains, is slow when belowfreezing temperatures persist. The second major snow storm (E3 in Fig. 4) was observed on DOY 37. It added $15 \mathrm{~cm}$ of snow for an aggregate snow depth of $38 \mathrm{~cm}$. This increase of snow depth increased brightness temperature polarization difference by $5 \mathrm{~K}$ at $37 \mathrm{GHz}$ and by $8-12 \mathrm{~K}$ at $89 \mathrm{GHz}$. The increase in TB in $89 \mathrm{GHz}$ reduces the TB gap between 37 and $89 \mathrm{GHz}$ for short period of time till the snow aged. The reduction in snow depth without the snow melting during events E4 and E5 is mainly due to high wind gusts, recorded at around 30 and 36 miles per hour, respectively

In the second half of February (DOY 49-51), a storm system with heavy clouds moved into the study area bringing warmer air that caused the snow temperature profile to collapse to the melting point, indicating snowmelt and wet snowpack formation. Warm daytime air temperatures with increased sensible heat flux of approximately $100 \mathrm{~W} \mathrm{~m}^{-2}$ raised the snowpack temperature to the freezing point and 
caused about $13 \mathrm{~cm}$ snowmelt. This snowmelt in the top layer brought the brightness temperatures of 37 and $89 \mathrm{GHz}$ closer, with the convergence and slightly higher value for $\mathrm{Tb}$ at $37 \mathrm{GHz}$ associated with the increase in wetness. Refreezing of melted snow in the top layer formed a 5-cm-thick ice layer after this warming episode. During the melting and refreezing period, the average modeled values of latent and sensible heat flux were $46.15 \mathrm{~W} \mathrm{~m}^{-2}$ and $-8.38 \mathrm{~W} \mathrm{~m}^{-2}$. Except for melting events (E6) the sensible and latent heat fluxes had opposite signs through the mid-winter period.

\subsubsection{Melting and refreezing phase}

The melting and refreezing phase, from DOY 58-87, includes 2 major snowfall events and major snowmelt events. The observed average, minimum and maximum snowpack temperature was 271.3, 266.4 and $273.1 \mathrm{~K}$, respectively. During this phase, reduction in snow depth was due to a major snowmelt of $22.5 \mathrm{~cm}$ on DOY 71-72 and some minor reductions due to snow blowing by wind. The average soil temperature during this period was $272.5 \mathrm{~K}$, which is warmer by $3.6 \mathrm{~K}$ compared to the snow accumulation phase. This soil temperature close to freezing point promotes wet snow conditions.

The combination of above freezing temperatures during daytime and below freezing temperatures at night caused multiple freezing and melting events in the snowpack. During daytime, solar radiation causes snowmelt in the upper layer, producing higher water content in top layers than deeper snow. These melting and refreezing events caused a large diurnal variation in the microwave brightness temperature during this period. The ice layer that formed after the snowmelt on DOY 50 (E6 in Fig. 4) was buried following a snowfall that occurred on DOY 59 and added about $15 \mathrm{~cm}$ of snow depth (E7 in Fig. 5). The temperature profile does not provide any evidence of the ice layer since the thickness of the ice layer was less than the vertical interval between the thermocouples. This ice layer within the snowpack amplified the BT polarization difference and reduced the brightness temperature by $50 \mathrm{~K}$ in $37 \mathrm{H}$ and $40 \mathrm{~K}$ in $37 \mathrm{~V}$.

Snow melting and refreezing events were observed in the middle of March 2011 starting from DOY 70. The sharp increase in the brightness temperature during melting is caused by liquid water in the top layer of snowpack. In the case of wet snow, the collapsing of 37 and $89 \mathrm{GHz}$ brightness temperatures shows the effect of real part of the dielectric constant of wet snow related to liquid water content and independent of snow grain size (Tiuri et al., 1984). During melting and refreezing, the changes in the 37 and $89 \mathrm{GHz}$ brightness temperatures were consistent and correlated with the snowpack temperature change measured by temperature profile (Event E10 in Fig. 5). This is likely associated with the presence of liquid water in the snowpack. The changes in the BT polarization difference appear to follow the daily temperature change.
Snowmelt processes are complex and difficult to distinguish using single microwave frequencies as water coated snow particles are highly emissive when compared to dry or wet soil (Grody, 1988). The BT polarization difference of melting snow (E8, E9 and E10 in Fig. 5) is almost equal to the polarization difference inherent to dry snow (Fig. 3). This melting and refreezing can build a relatively thick ice layer, which keeps the microwave emission much lower during cold days (Event E11 in Fig. 5).

During the melting and refreezing phase, the average modeled values of sensible heat flux were $51.0 \mathrm{~W} \mathrm{~m}^{2}$ with large variations (standard deviation $35.8 \mathrm{~W} \mathrm{~m}^{-2}$ ), indicating an input of heat into the snowpack. Similarly, latent heat flux also attained a peak of $145 \mathrm{~W} \mathrm{~m}^{-2}$ during melting phase. The latter was caused by warmer air temperature and heavy evaporation. These variations in the higher and lower values of latent and sensible heat flux were clearly noticed during the melting and refreezing period.

This time series analysis suggests that the grain size and snow wetness is an important parameter for understanding snowpack microwave properties during melting and refreezing of snow. The physical temperature profile in the snowpack can be used as a proxy for the liquid water content of wet snow.

\subsection{Classification analysis of brightness temperature for snowpack conditions}

As we discussed above, the microwave brightness temperature at 37 and $89 \mathrm{GHz}$ varies with changing snowpack physical properties, independent of snow depth. The temporal variation in snowpack was analyzed by classifying the snowpack into several categories. Classification was based on the radiometric measurements and in situ observations. All snowpacks were assigned to one of the following snow categories: (a) Fresh Snow (Shallow) (b) Fresh Snow (Deep) (c) Aged Snow, (d) Melting Snow, and (e) Refreezing Snow. Supervised classification analysis was carried out to understand and discriminate between different snow conditions based on the polarization difference and the spectral gradient of microwave BT observed at the 37 and $89 \mathrm{GHz}$.

Typical signatures of selected snow categories were derived from the cluster means and ranges for the polarization difference and spectral gradient of BTs at 37 and $89 \mathrm{GHz}$. Fig. 6 shows the mean brightness temperature values for five snow categories. The brightness temperature statistics in terms of range, mean, and standard deviation for the snow categories are given in Table 1.

The fresh dry snow and refreezing snow conditions are better distinguished from other clusters compared to the aged and wet snow conditions. Higher $\mathrm{Tb}$ values are related to melting snow compared to dry snow (Brucker et al., 2011). Figure 6 clearly shows the decrease in BT for fresh and aged snow covered surfaces. This decrease is a unique feature of snow and can therefore be used as reliable indicator of dry 
Table 1. Observed statistics of brightness temperature for snow conditions.

\begin{tabular}{|c|c|c|c|c|c|c|c|c|c|c|c|c|c|c|c|c|}
\hline \multirow[b]{2}{*}{ Snow Class } & \multicolumn{4}{|c|}{$37 \mathrm{H}$} & \multicolumn{4}{|c|}{$37 \mathrm{~V}$} & \multicolumn{4}{|c|}{$89 \mathrm{H}$} & \multicolumn{4}{|c|}{$89 \mathrm{~V}$} \\
\hline & Min. & Max. & Mean & Std & Min. & Max. & Mean & Std & Min. & Max. & Mean & Std & Min. & Max. & Mean & Std \\
\hline Shallow Fresh & 250.8 & 256.6 & 253.2 & 1.2 & 261.4 & 265.5 & 263.0 & 0.9 & 231.1 & 248.4 & 237.6 & 3.3 & 247.4 & 256.7 & 250.6 & 1.9 \\
\hline Deep Fresh & 230.7 & 237.3 & 232.8 & 1.3 & 249.4 & 251.9 & 250.4 & 0.6 & 175.6 & 197.2 & 185.2 & 4.6 & 197.8 & 212.4 & 204.2 & 4.0 \\
\hline Aged & 176.4 & 183.2 & 179.0 & 1.8 & 209.9 & 215.3 & 212.6 & 1.1 & 119.7 & 144.2 & 127.2 & 4.7 & 137.7 & 162.1 & 147.3 & 4.6 \\
\hline Melting & 166.6 & 267.0 & 239.9 & 26.2 & 179.1 & 269.2 & 252.6 & 24.6 & 130.7 & 257.4 & 223.9 & 31.2 & 142.3 & 263.8 & 238.4 & 28.7 \\
\hline Refreezing & 173.8 & 240.9 & 220.2 & 19.1 & 187.9 & 257.8 & 236.5 & 19.2 & 118.4 & 233.5 & 162.3 & 30.8 & 129.7 & 236.0 & 179.1 & 32.7 \\
\hline
\end{tabular}
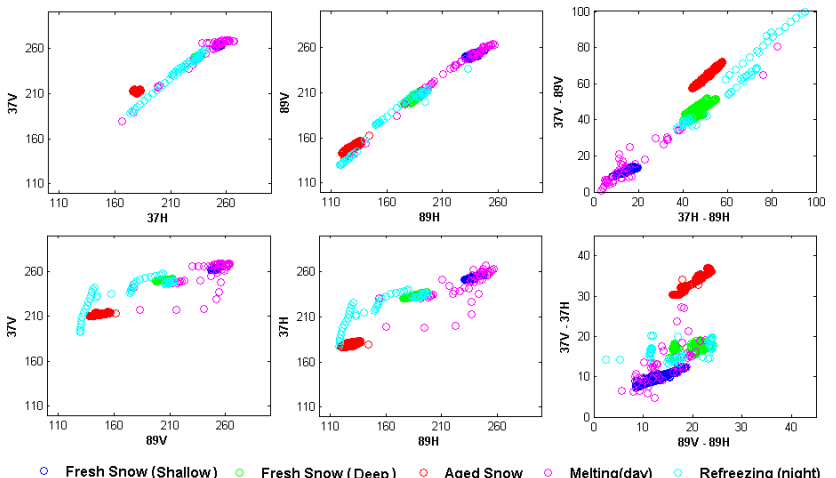

Fig. 6. Classification analysis of microwave observation for different snow conditions.

snow (Grody, 1988). Higher BT values at 37 and $89 \mathrm{GHz}$ with smaller depolarization factors, associated with melting snow conditions, are correlated with observed higher snow temperatures. The brightness temperature values for melting (wet) snow conditions are higher than BTs of other three snow categories. These higher values are due to liquid water in wet snow that can absorb and re-emit the microwave radiation. Further, the smaller BT difference between 37 and $89 \mathrm{GHz}$ during wet snow condition can help separate this cluster. A larger depolarization value at $37 \mathrm{GHz}$ separates the aged snow and/or the ice-covered snow conditions. The refrozen snow can be distinguished from other snow categories by lower BT at $37 \mathrm{GHz}$. This is caused by larger snow crystals formed during melting and refreezing that reduce the microwave emission of the snowpack. The distinct microwave signature of melting and refreezing conditions could be due to a combination of greater absorption by the water, and less scattering since the water is no longer in the original snowflake structure, which has many more ice facets to scatter the radiation.

Aged snow can be easily separated from fresh snow for lower and higher depth classes through independent or copolarized measurements. This preliminary analysis shows that these snow classes can be reliably discriminated or identified using available microwave measurements. However, we believe that recommendation of a general purpose algorithm would be premature until we process at least two more winter seasons of radiometric and snow observations.
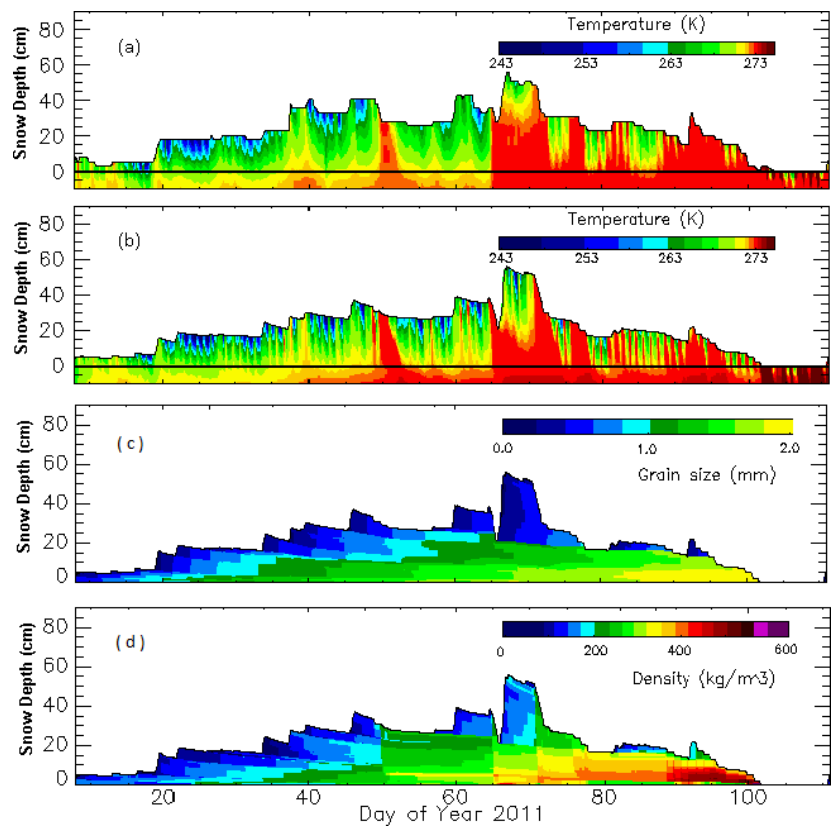

Fig. 7. Comparison of (a) observed temperature with (b) simulated snowpack temperature, (c) simulated snow grain size and (d) simulated snow density at varying snow depth.

\subsection{Simulations and comparisons}

\subsubsection{Snowpack properties using SNTHERM}

SNTHERM (SNow THERmal Model) is a one-dimensional mass and energy balance model (Jordan, 1991) used to simulate snowpack properties (including snow grain size and density). Meteorological data including solar radiation, air temperature, humidity, wind speed, cloud cover parameters and precipitation were used as an input to SNTHERM to simulate the snow depth, snow grain size, density and the snowpack temperature as shown in Fig. 7. Overall, the simulated and observed hourly snow depth and snowpack temperatures agree quite well through the season. A strong correlation $\left(r^{2}=0.946\right)$ is found for snow depth with root mean square error (RMSE) of $4 \mathrm{~cm}$. During cold, dry periods, SNTHERM was unable to represent the few centimeters of snow depth reduction observed due to wind blowing. Similarly, the correlation coefficient between simulated and 
Table 2. Statistical comparison of observed and modeled (SNTHERM) soil and snowpack temperature above and below soil surface.

\begin{tabular}{lrr}
\hline $\begin{array}{l}\text { Sensor } \\
\text { Level }(\mathrm{cm})\end{array}$ & $\begin{array}{r}\text { Correlation } \\
\text { Coefficient }(R)\end{array}$ & $\begin{array}{r}\text { Mean Absolute Difference } \\
(\mathrm{MSD}) \text { in }{ }^{\circ} \mathrm{C}\end{array}$ \\
\hline $\mathrm{T}(-10)$ & 0.813 & 0.695 \\
$T(-5)$ & 0.834 & 0.541 \\
$T(0)$ & 0.847 & 0.744 \\
$T(5)$ & 0.850 & 1.091 \\
$T(10)$ & 0.905 & 1.161 \\
$T(15)$ & 0.910 & 2.050 \\
$T(20)$ & 0.803 & 1.895 \\
$T(25)$ & 0.759 & 3.383 \\
$T(30)$ & 0.733 & 2.636 \\
$T(38)$ & 0.507 & 2.335 \\
$T(46)$ & 0.877 & 2.784 \\
$T(53)$ & 0.881 & 3.595 \\
\hline
\end{tabular}

observed snowpack temperature exceeded 0.8 , and for the soil temperature the mean absolute difference between simulated and observed values was less than $1.0^{\circ} \mathrm{C}$ (Table 2). However, the snowpack temperature observed close to the snow surface showed larger differences $\left(2-30^{\circ} \mathrm{C}\right)$ in the simulated values. SNTHERM soil temperatures at 5 and $10 \mathrm{~cm}$ below ground surface were consistently higher than observations in the later part of study period.

The simulated snow grain size and density was validated using field measurements at snow pits on DOY 69 (Fig. 8). The SNTHERM estimates of grain size were fairly accurate with average RMSE $0.237 \mathrm{~mm}$. The RMSE is lower near the top of the snowpack. Similarly, the RMSE of snow density measurements was $20.35 \mathrm{~kg} \mathrm{~m}^{-3}$, and again is lower near the top. It should be noted that SNTHERM failed to simulate the 5 -cm-thick ice layer actually observed in the snow pits. This ice layer was formed during DOY 49-51 snowmelt and later sandwiched by fresh snowfall on DOY 60 .

This aspect of validating SNTHERM is limited because grain size and density profiles were only measured once during the season. In future field seasons, we expect to measure these parameters regularly and therefore be better able to compare their evolution with SNTHERM. This good overall performance of SNTHERM compared to available measurement of snowpack depth, temperature, and snow grain size and density prompted us to use the simulated SNTHERM time series of snow grain size and density in the HUT microwave snow emission model to conduct a preliminary evaluation of its ability to simulate the observed evolution of microwave brightness temperatures.

\subsubsection{Brightness temperature using HUT snow emission model}

The HUT (Helsinki University of Technology) snow emission model is a semi-empirical model based on radiative
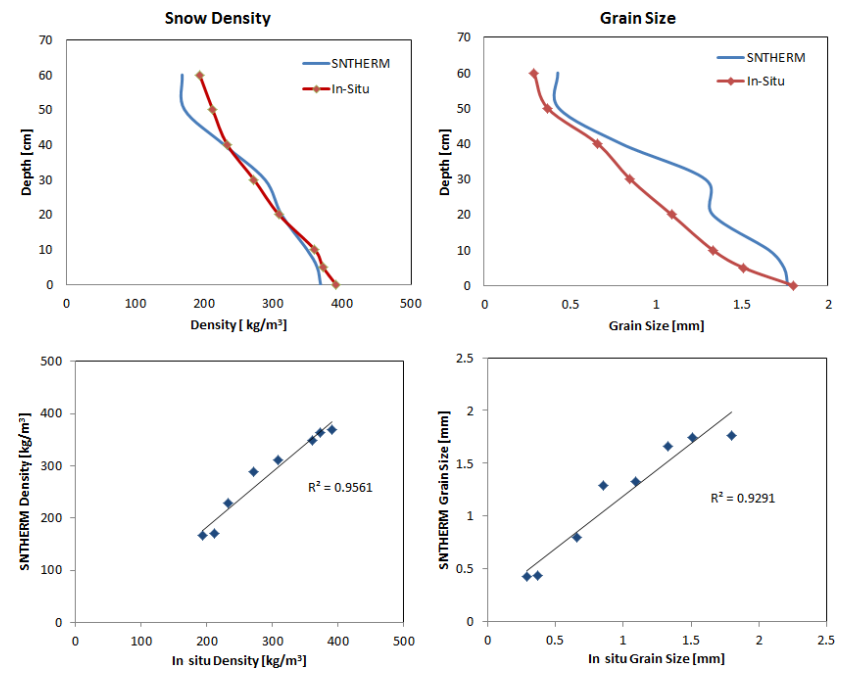

Fig. 8. Validation of SNTHERM simulated snow grain size and density using measured snow grain size and density from snow pit data taken on DOY 69.

transfer theory (Pulliainen et al., 1999). The model considers the snowpack as a homogenous layer, and uses effective values for parameters affecting the scatter of microwave radiation in the snowpack, including snow depth, density and grain size. A combination of measured and simulated (SNTHERM) snowpack characteristics, given at hourly temporal resolution, were used as the input variables to run the HUT snow emission model in order to simulate $\mathrm{Tb}$ at 37 and $89 \mathrm{GHz}$ for both vertical $(\mathrm{V})$ and horizontal $(\mathrm{H})$ polarizations (Fig. 9). The simulated snow grain size and density from SNTHERM were used along with measured snowpack temperature and snow depth as the input to the HUT model. The measured soil temperature at the soil surface and $5 \mathrm{~cm}$ depth were averaged and used as the soil temperature input to the HUT model. The simulation period covers 8 January to 29 March 2011, thus encompassing the full snowpack seasonal evolution described in Sect. 3.1. This long period allows us to evaluate the HUT model under various weather conditions, different soil and snow temperatures, and extensive melting and refreezing periods. Atmospheric effects on the estimated brightness temperature were neglected, since the microwave data were acquired from a ground-mounted radiometer a minimal distance from the snowpack.

Figure 9 shows a comparison of simulations of brightness temperature with ground-based radiometer measurements at 37 and $89 \mathrm{GHz}$ frequencies. Broadly, there is some agreement between the seasonal patterns of modeled and simulated brightness temperatures, such as the gradual decrease with snow accumulation over days 8-60 and the increase with melt onset around day 65 . However, the diurnal cycle and synoptic variability is generally not well simulated, with observations generally showing more variability in these timescales than the simulation. 


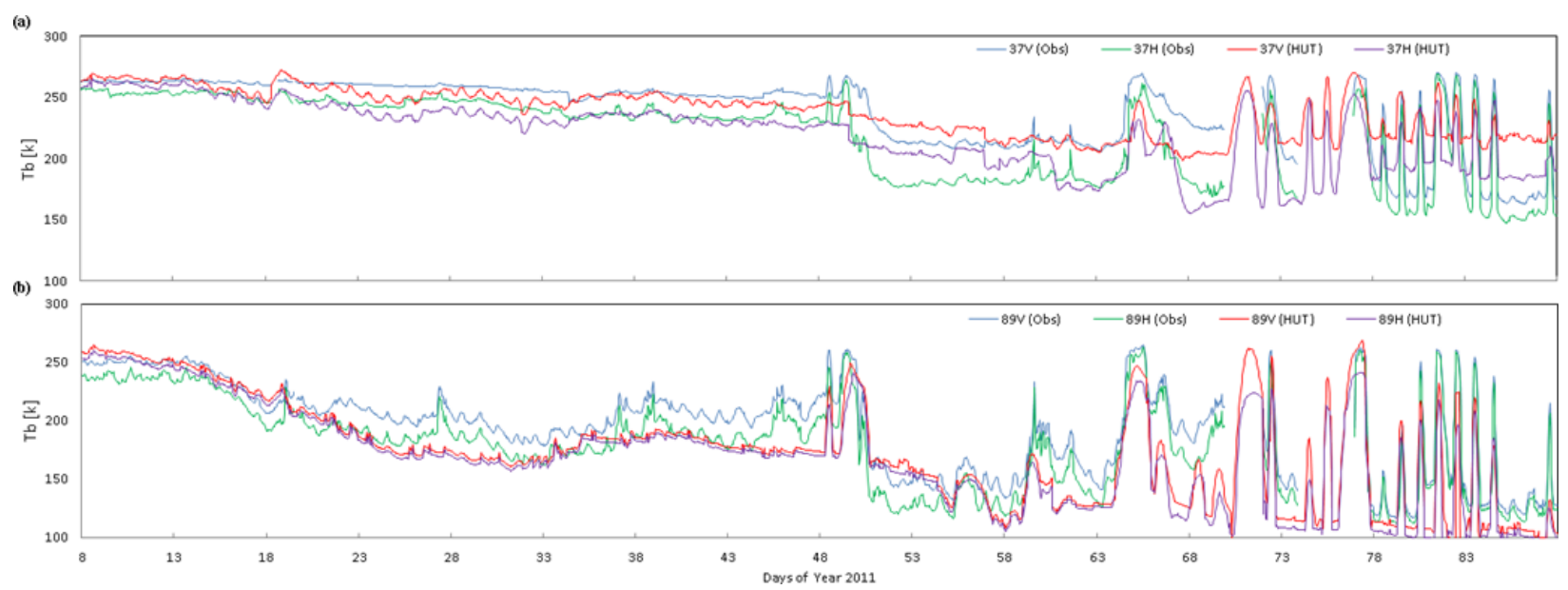

Fig. 9. Comparison of hourly simulated (HUT) and observed brightness temperature for (a) 37 and (b) $89 \mathrm{GHz}$ for entire snow season.

When the snowpack is dry during snow accumulation phase, the mean absolute difference between observed and simulated $\mathrm{Tb}$ for $37 \mathrm{~V}, 37 \mathrm{H}, 89 \mathrm{~V}$, and $89 \mathrm{H}$ is $7.37,7.91$, 19.18 and $13.85 \mathrm{~K}$, respectively. $89 \mathrm{GHz}$ show small differences for shallow depth during DOY 8-20, which increases when the snow is deeper. During the subfreezing and melting phase the differences between observed and simulated $\mathrm{Tb}$ for $37 \mathrm{~V}, 37 \mathrm{H}, 89 \mathrm{~V}$, and $89 \mathrm{H}$ are larger, at $10.16,14.33,25.31$ and $20.85 \mathrm{~K}$, respectively. Similarly, during the melting and refreezing phase, the differences in observed and simulated $\mathrm{Tb}$ for $37 \mathrm{~V}, 37 \mathrm{H}, 89 \mathrm{~V}$, and $89 \mathrm{H}$ are even larger, at 29.74 , $24.52,40.25$, and $35.81 \mathrm{~K}$, respectively. However, the discrepancy in brightness temperature between model and observations for $37 \mathrm{GHz}$ was consistently lower compared to $89 \mathrm{GHz}$.

One possible reason for the relatively large discrepancies seen is the use of simulated (SNTHERM), rather than measured, snow grain size and density values for simulation of brightness temperature using the HUT snow emission model. We plan to study the SNTHERM and HUT model performance in more detail in future work with the help of continuous measurements of snow grain size and density.

\section{Conclusions}

In the initial phase of the CREST-SAFE field experiment, carried out during January to March 2011 and reported here, microwave and surface observations were collected to analyze the snowpack seasonal change and its impact on the passive microwave emission of the snowpack. We found that both the snow grain size and the snow temperatures affect the brightness temperature at 37 and $89 \mathrm{GHz}$. The simulated snowpack temperature using SNTHERM has shown good correlation with the observed in situ snowpack temperature. This type of long-term field experiment helps to improve our understanding of microwave radiative transfer during melting-refreezing, snow metamorphism, and under various meteorological conditions.

More measurements are needed to quantify the thickness of ice layers at the surface and within the snowpack and its impact on microwave emission. The effects of sensible heat flux, relative humidity and other meteorological parameters (including the wind effects which speed up the melting and refreezing processes) on changes of the snow grain size are still not understood completely and need more data and analysis. The largest discrepancies between our measurements and models of snowpack evolution and microwave radiative transfer models were seen during the snowmelt period, when we observed large diurnal variations in the microwave brightness temperature associated with melting-refreezing cycles. More research is required to understand the effects of changing snowpack properties on the microwave measurements. This is important for accurate retrievals of ground snow conditions from satellite microwave measurements.

The recent upgrade to the CREST-SAFE facility includes the addition of new instruments to measure solar radiation, soil moisture (at $2.5,5$, and $10 \mathrm{~cm}$ ), snow skin temperature, air temperature, humidity, snow weight, snow depth, and rain/snowfall. Starting in the winter season of 2012-2013, snow pillows will be used to measure snow water equivalent by weight displacement. Snow depth will be measured with an ultrasonic snow depth sensor each minute. Future research work using this enhanced suite of instruments will include quantifying the thickness of ice layers at the surface and within the snowpack caused by melting and refreezing of snow and ice and their effect on microwave emissivity. The effect of within-snowpack temperature gradients on snow grain size and microwave emission will be investigated further using multilayer snowpack radiative transfer models. The impact of the seasonal behavior of snow grain size on brightness temperature will be better quantified. The continuation of long-term observations of in situ snow properties 
combined with microwave radiances will facilitate the assessment of current snow retrieval algorithms and their capability to infer snow properties under different meteorological conditions.

Acknowledgements. This study was supported by National Oceanic and Atmospheric Administration (NOAA) under grant numbers NA06OAR4810162, NA11SEC4810004 and NA09NES4400006. The views, opinions, and findings contained in this report are those of the authors and should not be construed as an official National Oceanic and Atmospheric Administration or US Government position, policy, or decision. The authors also acknowledge Peter Rahe and Bill Desjardins from NOAA's National Weather Service in Caribou, Maine for their help in the experiment setup. Thanks to Fred Solheim and team from the Radiometric Corporation for their quick help in instrument calibration and operation, and thanks to J. Pulliainen and Juha Lemmetyinen from Helsinki University of Technology for providing the HUT model. Thanks to Marouane Temimi for useful discussion and comments on preparation of the experiment and this manuscript.

Edited by: A. Gelfan

\section{References}

Brucker, L., Royer, A., Picard, G., Langlois, A., and Fily, M.: Hourly simulations of the microwave brightness temperature of seasonal snow in Quebec, Canada, using a coupled snow evolution-emission model, Remote Sens. Environ., 115, 19661977, doi:10.1016/j.rse.2011.03.019, 2011.

Chang, A. T. C., Foster, J. L., Hall, D. K., Rango, A., and Hartline, B. K.: Snow water equivalent determination by microwave radiometry, Cold Reg. Sci. Technol., 5, 259-267, 1981.

Chang, A. T. C., Kelly, R. E. J., Foster, J. L., and Hall, D. K.: Global SWE monitoring using AMSR-E data, Geoscience and Remote Sensing Symposium, IGARSS'03, Proceedings., 1, 680682, doi:10.1109/IGARSS.2003.1293880, 2003.

Durand, M., Kim, E. J., and Margulis, S. A.: Quantifying Uncertainty in Modeling Snow Microwave Radiance for a Mountain Snowpack at the Point-Scale, Including Stratigraphic Effects, IEEE T. Geosci. Remote, 46, 1753-1767, doi:10.1109/TGRS.2008.916221, 2008

Elder, K., Cline, D., Liston, G. E., and Armstrong, R.: NASA Cold Land Processes Experiment (CLPX 2002/03): Field Measurements of Snowpack Properties and Soil Moisture, J. Hydrometeorol., 10, 320-329, doi:10.1175/2008JHM877.1, 2009.

Erman, D. C., Andrews, E. D., and Yoder-Williams, M.: Effects of Winter F oods on Fishes in the Sierra Nevada, Can. J. Fish Aquat. Sci., 45, 2195-2200, 1988.

Foster, J. L., Chang, A. T. C., and Hall, D. K.: Comparison of Snow Mass Estimates from a Prototype Passive Microwave Snow Algorithm, a Revised Algorithm and a Snow Depth Climatology, Remote Sens. Environ., 62, 132-142, 1997.

Grody, N. C.: Surface identification using satellite microwave radiometers, IEEE T. Geosci. Remote, 26, 850-859, 1988.

Grody, N. C.: Relationship between snow parameters and microwave satellite measurements: Theory compared with Advanced Microwave Sounding Unit observa- tions from 23 to $150 \mathrm{GHz}$, J. Geophys. Res., 113, 1-17, doi:10.1029/2007JD009685, 2008.

Grody, N. C. and Basist, A. N.: Global identification of snowcover using SSM/I measurements, IEEE T. Geosci. Remote, 34, 237249, doi:10.1109/36.481908, 1996.

Hewison, T. J. and English, S. J.: Airborne retrievals of snow and ice surface emissivity at millimeter wavelengths, IEEE T. Geosci. Remote, 37, 1871-1879, doi:10.1109/36.774700, 1999.

Jordan, R.: A One-Dimensional Temperature Model for a Snow Cover: Technical Documentation for SNTHERM.89, US Army Corps of Engineers, Cold Regions Research and Engineering Laboratory, 1991.

Kelly, R. E., Chang, A., Tsang, L., and Foster, J. L.: A prototype AMSR-E global snow area and snow depth algorithm, IEEE T. Geosci. Remote, 41, 230-242, 2003.

Kongoli, C., Grody, N. C., and Ferraro, R. R.: Interpretation of AMSU microwave measurements for the retrievals of snow water equivalent and snow depth, J. Geophys. Res., 109, 1-12, doi:10.1029/2004JD004836, 2004.

Langlois, A., Barber, D. G., and Hwang, B. J.: Development of a winter snow water equivalent algorithm using in situ passive microwave radiometry over snow-covered first-year sea ice, Remote Sens. Environ., 106, 75-88, doi:10.1016/j.rse.2006.07.018, 2007.

Langlois, A., Kohn, J., Royer, A., Cliche, P., Brucker, L., Picard, G., Fily, M., Derksen, C., and Willemet, J. M.: Simulation of Snow Water Equivalent (SWE) Using Thermodynamic Snow Models in Québec, Canada, J. Hydrometeorol., 10, 1447-1463, doi:10.1175/2009JHM1154.1, 2009.

Macelloni, G., Paloscia, S., Pampaloni, P., Brogioni, M., Ranzi, R., and Crepaz, A.: Monitoring of melting refreezing cycles of snow with microwave radiometers: the Microwave Alpine Snow Melting Experiment (MASMEx 2002-2003), IEEE T. Geosci. Remote, 43, 2431-2442, doi:10.1109/TGRS.2005.855070, 2005.

McCabe, G. J., Hay, L. E., and Clark, M. P.: Rain-on-Snow Events in the Western United States, B. Am Meteorol. Soc., 88, 319328, doi:10.1175/BAMS-88-3-319, 2007.

Papa, F., Prigent, C., and Rossow, W. B.: Ob' River flood inundations from satellite observations: A relationship with winter snow parameters and river runoff, J. Geophys. Res., 112, 1-11, doi:10.1029/2007JD008451, 2007.

Pulliainen, J., Grandell, J., and Hallikainen, M. T.: HUT snow emission model and its applicability to snow water equivalent retrieval, IEEE T. Geosci. Remote, 37, 1378-1390, 1999.

Romanov, P., Gutman, G., and Csiszar, I.: Automated monitoring of snow cover over North America with multispectral satellite data, J. Appl. Meteorol., 39, 1866-1880, 2000.

Rosenfeld, S. and Grody, N. C.: Metamorphic signature of snow revealed in SSM/I measurements, IEEE T. Geosci. Remote, 38, 53-63, doi:10.1109/36.823901, 2000.

Simic, A., Fernandes, R., Brown, R., Romanov, P., and Park, W.: Validation of VEGETATION, MODIS, and GOES+SSM/I snow-cover products over Canada based on surface snow depth observations, Hydrol Process., 18, 1089-1104, doi:10.1002/hyp.5509, 2004.

Singh, P., Spitzbart, G., Hubl, H., and Weinmeister, H. W.: Hydrological response of snowpack under rain-on-snow events: a field study, J. Hydrol., 202, 1-20, doi:10.1016/S0022-1694(97)000048, 1997. 
Tiuri, M., Sihvola, A., Nyfors, E., and Hallikaiken, M.: The complex dielectric constant of snow at microwave frequencies, IEEE J. Oceanic Eng., 9, 377-382, doi:10.1109/JOE.1984.1145645, 1984.

Ulaby, F. T. and Stiles, W. H.: The Active and Passive Microwave Response to Snow Parameters 2. Water Equivalent of Dry Snow, J. Geophys. Res., 85, 1045-1049, doi:10.1029/JC085iC02p01045, 1980.
Wiesmann, A. and Mätzler, C.: Microwave Emission Model of Layered Snowpacks, Remote Sens. Environ., 70, 307-316, doi:10.1016/S0034-4257(99)00046-2, 1999. 